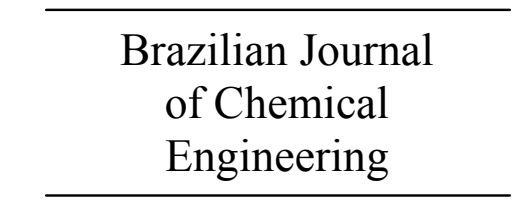

ISSN 0104-6632

Printed in Brazil

www.abeq.org.br/bjche

Vol. 30, No. 01, pp. 159 - 166, January - March, 2013

\title{
MATHEMATICAL MODELING OF SUPERCRITICAL FLUID EXTRACTION OF OIL FROM CANOLA AND SESAME SEEDS
}

\author{
B. Honarvar ${ }^{1 *}$, S. A. Sajadian ${ }^{2}$, M. Khorram ${ }^{2}$ and A. Samimi ${ }^{2}$ \\ ${ }^{1}$ Chemical Engineering Department, Science \& Research Branch, Phone: + 989173145175 , \\ Fax: + 987116247155, Islamic Azad University, Fars, Shiraz, Iran. \\ E-mail: honarvar2@gmail.com \\ ${ }^{2}$ Chemical Engineering Department, University of Sistan and Baluchestan, Zahedan, Iran.
}

(Submitted: November 14, 2011 ; Revised: April 20, 2012 ; Accepted: April 20, 2012)

\begin{abstract}
Mathematical modeling of supercritical fluid extraction of oil from canola and sesame seeds with a two-phase model was performed in this work. A model based on differential mass balance was used to correlate the experimental data. Different adsorption isotherm models (Henry, Freundlich and Brunauer, Emmet and Teller (BET)) were used to describe the equilibrium state. Three model parameters such as effective diffusivity $\left(\mathrm{D}_{\text {eff }}\right)$, mass transfer coefficient $\left(\mathrm{K}_{\mathrm{f}}\right)$ and axial dispersion coefficient $\left(\mathrm{D}_{\mathrm{ax}}\right)$ of the bed were used as fitting parameters. The experimental data for yields were obtained at pressures of 10-20 MPa, temperatures of 313-333 K and solvent flow rates of 2-4 g/min. From the results, a nonlinear adsorption isotherm exhibited better agreement with experimental data of yield than a linear model in the range of studied conditions.

Keywords: Mathematical modeling; Interaction solute-solid; Isotherm; BET; Freundlich.
\end{abstract}

\section{INTRODUCTION}

Mathematical models are powerful and useful tools for design and scale up of SCFE processes and, since the laboratory scale up to pilot and industrial scales and the cost evaluation of processes cannot be done without mathematical modeling, several attempts at mathematical modeling of supercritical fluid extraction processes have been proposed. Three different approaches have been proposed for SFE mathematical modeling. The first approach is based on the use of an empirical kinetic equation to describe experimental data (Naik et al., 1989; Ngueyn et al., 1991; Subra et al., 1998; Silva et al., 2008). These empirical relations are useful when there is no information about equilibrium relations and mass transfer mechanisms. Their advantage is their simplicity, but these models are not adequate for scaling up. Other authors have proposed models based on analogies to heat and mass transfer (Bartle et al., 1990; Reverchon et al., 1993; Esquivel et al., 1999; Barroso et al., 2011). The single sphere model assumes that the solute is extracted from a particulate bed composed of porous and inert spheres having the same size; the model showed that intraparticle mass transfer was the controlling factor for the process and that mass transfer resistance on the fluid is zero. Another approach to SFE modeling is based on differential mass balance, such as the "broken and intact cells" model. Sovová (1994) presented a general model that divides the extraction curve into two main periods. The initial period occurs while the extraction rate is constant. It is controlled by the solubility between solute and solvent (phase equilibrium) and external mass transfer. The second part considers that internal diffusion controls only the extraction of less accessible oil and occurs during this period. Goto et al. (1996) applied the shrinking

*To whom correspondence should be addressed 
core model to describe extraction of ginger root with supercritical fluid. This model assumes that the solute is condensed within pores in solid particles and a sharp boundary develops between an oil-rich core in the porous particle and an extracted outer region where the core shrinks as the extraction proceeds. Goodarznia and Ekani (1998) proposed an unsteady state mass balance for solute in a single particle coupled with a fluid phase balance on a differential section of the bed. Internal diffusivity, mass transfer coefficient to the bulk phase and the effect of axial dispersion in the fixed bed are parameters of the model. The extraction of triglycerides from used frying oil with liquid and supercritical ethane has been studied in a semi-batch system at different operating conditions by Rincon et al. (2011) and kinetics and selectivity of supercritical carbon dioxide (SC CO2) extraction of Helichrysum italicum flowers were analyzed at different operating conditions by Ivanovic et al. (2001). Rosmarinus officinalis (rosemary) extracts were obtained in a supercritical pilot-scale plant based on experimental information available in the literature for analytical or low-scale processes under different operating conditions by Garcia-Risco (2011).

The scope of this study was the supercritical fluid extraction oil of canola and sesame seeds oil performed under some different operating conditions. The experimental results were used to develop a model of the extraction process. Many researchers have considered the Henry isotherm because the Henry relation is simple and linear (Goto et al.,
1996; Reverchon, 1997; Gooderznia and Ekani, 1998; Reverchon, 2001; Carvalho et al., 2012). Goto et al. (1998) proposed a Brunauer, Emmet and Teller (BET)-type equilibrium relationship for SFE processes where the solute interacts with the solid matrix. Fatemi et al. (2008) applied different isotherms (Henry, Langmuir, Freundlich and Toth) to describe the interaction between solute-solid in the extraction of valerenic acid from Valeriana officinalis L. Ghoreishi et al. (2001) employed the Freundlich isotherm for the modeling of supercritical extraction of mannitol from pane tree leaf. In this work, linear (Henry) and nonlinear adsorption (BET, Freundlich) were used to describe the interaction between oil and seed. This model takes into account mass transfer, solute-fluid interaction (solubility) and solute-solid interaction (adsorption). At equilibrium, the distribution of solute between the solid phase and the supercritical phase is determined by the adsorption isotherm. The adsorption isotherm of oil in the supercritical fluid was modeled by using the different isotherms, such as a single parameter equilibrium relation (Henry), two-parameter relations (BET, Langmuir and Freundlich) and three-parameter relations (Langmuir-Freundlich and Toth).

\section{MATERIALS AND METHODS}

Figure 1 shows the schematic diagram of the extractor apparatus. The extraction experiments were carried out in a bench scale SC-CO2 apparatus.

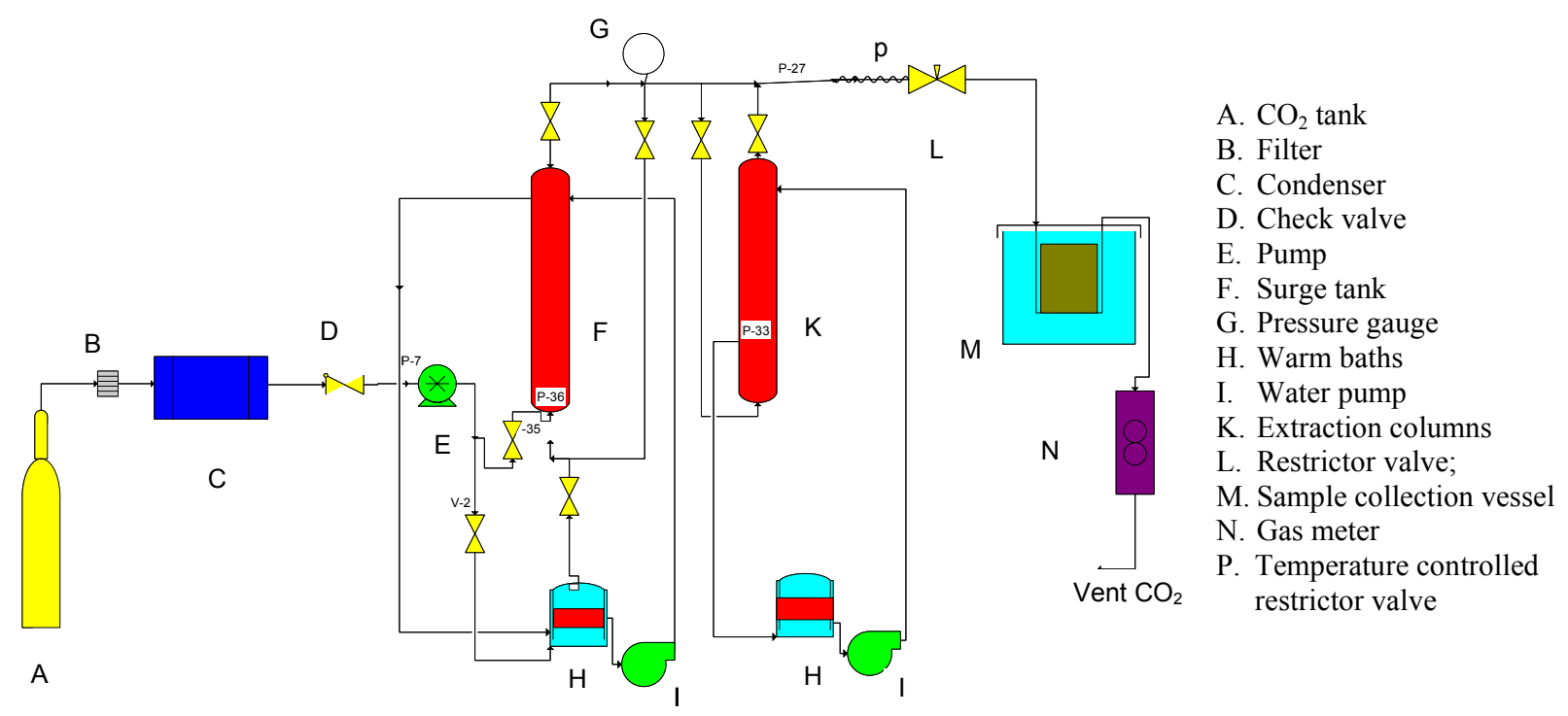

Figure 1: Schematic diagram of the extraction of oil from canola seed with supercritical carbon dioxide 
Carbon dioxide was fed from a gas tank equipped with a condenser to keep $\mathrm{CO}_{2}$ liquefied. A pump was used to pressurize the liquefied carbon dioxide to the desired pressure. In the present work, about $5 \mathrm{~g}$ of dried canola seeds and $0.5 \mathrm{~g}$ of ethanol (modifier) along with glass beads were loaded into a $60 \mathrm{~mL}$ high pressure vessel in which the glass beads were used to prevent flow channeling in the packed bed. The pressurized carbon dioxide was passed through a surge tank before feeding to the packed bed vessel. The surge tank and the extractor were equipped with a jacket through which hot water flows to control the temperature. In this study, the static time was considered to be about 30 minutes by feeding SC$\mathrm{CO} 2$ to the vessel while the outlet back pressure valve was closed. The dynamic conditions began when the flow of solvent through the vessel was allowed by opening the back pressure valve. To prevent the back pressure valve from freezing, it was heated by an electrical resistance. The extracted oil was transferred to liquid dichloromethane solvent in a u-tube separator where the released $\mathrm{CO}_{2}$ gas was metered by a gas flow meter. The temperature of the solvent was kept at below $0^{\circ} \mathrm{C}$ by using an ice and salt bath during the dynamic extraction time. The $99.6 \%$ ethanol and $99.9 \%$ dichloromethane were provided by Merck; while the $99.9 \% \quad \mathrm{CO}_{2}$ was obtained from Eritch Gas Co.

\section{MATHEMATICAL MODELING}

The experimental data were fitted with a two phase model. The model is based on the differential mass balances in the solid phase and supercritical phase which is suggested by Goodarznia and Ekani (1998) and Silva et al., (2011).

The following simplifying assumptions were made in the model formulations:

1. Temperature gradient and pressure drop through the bed are low enough to consider that the fluid density remains constant.

2. Solute is considered to be single chemical component.

3 . The flow regime is axially dispersed.

4. The physical properties of supercritical $\mathrm{CO}_{2}$ are constant.

5. The solvent flow rate was constant along the bed and uniformly distributed, without any radial dispersion.

6. The particle surface is porous.

According to the above assumptions, material balances in a volume element of packed bed column for the fluid and solid phases lead to:

\section{i) Bulk Fluid Phase}

$$
\begin{aligned}
& \frac{\partial \mathrm{C}}{\partial \mathrm{t}}+\mathrm{u}_{0} \frac{\partial \mathrm{C}}{\partial \mathrm{z}}= \\
& \mathrm{D}_{\mathrm{ax}} \frac{\partial^{2} \mathrm{C}}{\partial \mathrm{z}^{2}}+\mathrm{a}_{\mathrm{f}} \mathrm{k}_{\mathrm{f}} \frac{\left(1-\varepsilon_{\mathrm{b}}\right)}{\varepsilon_{\mathrm{b}}}\left(\mathrm{C}_{\mathrm{P}, \mathrm{Rp}}-\mathrm{C}\right)
\end{aligned}
$$

\section{ii) Solid Phase}

$$
\frac{\partial \mathrm{C}_{\mathrm{p}}}{\partial \mathrm{t}}+\frac{\left(1-\varepsilon_{\mathrm{p}}\right)}{\varepsilon_{\mathrm{p}}} \frac{\partial \mathrm{C}_{\mathrm{s}}}{\partial \mathrm{t}}=\frac{\mathrm{D}_{\text {eff }}}{\varepsilon_{\mathrm{p}} \mathrm{r}^{2}} \frac{\partial}{\partial \mathrm{r}}\left(\mathrm{r}^{2} \frac{\partial \mathrm{C}_{\mathrm{p}}}{\partial \mathrm{r}}\right)
$$

Based on one of the assumptions of the model, the surface of the particles is porous; the solute dissolves in the fluid phase. So linear (Henry) and nonlinear adsorption (BET, Freundlich) isotherms were tested for interaction between $\mathrm{C}_{\mathrm{s}}$ and $\mathrm{C}_{\mathrm{p}}$ that obtain by Table 1 .

Table 1: Adsorption isotherms and average absolute relative deviations from the experiments.

\begin{tabular}{|l|c|c|c|}
\hline $\begin{array}{l}\text { Adsorption } \\
\text { isotherm }\end{array}$ & Equation & $\begin{array}{c}\text { AARD } \\
\text { (\%) } \\
\text { Canola } \\
\text { seeds }\end{array}$ & $\begin{array}{c}\text { AAR D } \\
\text { (\%) } \\
\text { Sesame } \\
\text { seeds }\end{array}$ \\
\hline Henry & $\mathrm{C}_{\mathrm{s}}=\mathrm{HC}_{\mathrm{p}}$ & 8.77 & 9.84 \\
Freundlich & $\mathrm{C}_{\mathrm{s}}=\mathrm{KC}_{\mathrm{p}}^{\mathrm{n}}$ & 7.21 & 7.42 \\
$\begin{array}{l}\text { Brunauer, } \\
\text { Emmet and } \\
\text { Teller }\end{array}$ & $\left.\frac{\mathrm{C}_{\mathrm{s}}}{\mathrm{C}_{\mathrm{m}}}=\frac{\mathrm{C}_{\mathrm{p}}}{\left(1-\frac{\mathrm{C}_{\mathrm{p}}}{\mathrm{C}_{\mathrm{sat}}}\right)\left[1+(\mathrm{K}-1) \frac{\mathrm{C}_{\mathrm{p}}}{\mathrm{C}_{\mathrm{sat}}}\right.}\right]$ & & \\
\hline
\end{tabular}

Equations (1), (2) and the adsorption isotherms were solved subject to the following initial and boundary conditions:

$$
\begin{aligned}
& \mathrm{z}=0 ; \mathrm{t}>0: \frac{\partial \mathrm{C}_{\mathrm{p}}}{\partial \mathrm{z}}=0 \\
& \mathrm{z}=0 ; \mathrm{t}>0: \mathrm{D}_{\mathrm{ax}} \frac{\partial \mathrm{C}}{\partial \mathrm{z}}=\mathrm{u}_{0}\left(\mathrm{C}-\mathrm{C}_{0}\right) \\
& \mathrm{r}=\mathrm{R}_{\mathrm{p}} ; 0 \leq \mathrm{z} \leq \mathrm{H} ; \mathrm{t}>0:-\mathrm{D}_{\text {eff }} \frac{\partial \mathrm{C}_{\mathrm{p}}}{\partial \mathrm{r}}=\mathrm{k}_{\mathrm{f}}\left(\mathrm{C}_{\mathrm{p}}-\mathrm{C}\right) \\
& \mathrm{r}=0 ; 0 \leq \mathrm{z} \leq \mathrm{H} ; \mathrm{t}>0: \frac{\partial \mathrm{C}_{\mathrm{s}}}{\partial \mathrm{r}}=\frac{\partial \mathrm{C}_{\mathrm{p}}}{\partial \mathrm{r}}=0 \\
& \mathrm{t}=0 ; 0 \leq \mathrm{z} \leq \mathrm{H} ; 0 \leq \mathrm{r} \leq \mathrm{R}_{\mathrm{p}}: \mathrm{C}_{\mathrm{p}}=\mathrm{C}_{\mathrm{p}, 0}
\end{aligned}
$$




$$
\mathrm{t}=0 ; 0 \leq \mathrm{z} \leq \mathrm{H} ; 0 \leq \mathrm{r} \leq \mathrm{R}_{\mathrm{p}}: \mathrm{C}_{\mathrm{s}}=\mathrm{C}_{\mathrm{s}, 0}
$$

Mathematical model equations coupled with equilibrium relations were solved numerically by the Method of Lines available in MATLAB 7.1.

\section{Model Parameters}

\section{1) Mass Transfer Coefficient}

The film mass transfer coefficient $\mathrm{k}_{\mathrm{f}}$ around the particle was estimated using the empirical correlation reported by Tan et al. (1989).

$\mathrm{k}_{\mathrm{f}}=\frac{\mathrm{ShD}_{\mathrm{AB}}}{2 \mathrm{R}_{\mathrm{P}}}$

$\mathrm{Sh}=0.38 R \mathrm{e}^{0.83} \mathrm{Sc}^{0.33}$

\section{2) Axial Dispersion}

The axial dispersion coefficient in the SC phase was approximated by using the correlation given by Tan and Liou (1989).

$\mathrm{Pe}=1.634 \mathfrak{R} \mathrm{e}^{0.268} \mathrm{Sc}^{-0.919}$

$\mathrm{D}_{\mathrm{ax}}=\frac{\mathrm{u}_{0} \mathrm{~L}}{\mathrm{Pe}}$

\section{3) Effective Diffusivity}

The equation for the effective diffusivity in the particle was given by Prausnitz et al. (2001):

$\mathrm{D}_{\mathrm{eff}}=\varepsilon_{\mathrm{p}}^{2} \mathrm{D}_{\mathrm{AB}}$

\section{RESULTS AND DISCUSSION}

In the present model, the parameters, $\mathrm{D}_{\text {eff }}, \mathrm{D}_{\mathrm{ax}}, \mathrm{k}_{\mathrm{f}}$ and parameters of the equilibrium relations were determined by minimizing the errors:

$\operatorname{AARD}(\%)=\frac{1}{\mathrm{n}} \sum_{\mathrm{i}=1}^{\mathrm{n}} \frac{\left|\mathrm{y}_{\text {exp }}-\mathrm{y}_{\text {cal }}\right|}{\mathrm{y}_{\exp }} \times 100$

The adjustable parameters of the model for canola and sesame seeds are presented in Tables 2 and 3, respectively. The solute interactions in the solid matrix have been studied with the proposed equilibrium relationships (Henry, Freundlich and BET) and the average absolute relative deviation (AARD) determined for every isotherm given in Table 1. The BET isotherm model describes better the experimental data than Freundlich and Henry isotherm models, so the BET isotherm was used for mathematical modeling. The parameters of the BET isotherm are $\mathrm{K}$ and $\mathrm{C}_{\mathrm{m}}$, where $\mathrm{K}$ represents the equilibrium coefficient, and $\mathrm{C}_{\mathrm{m}}$, the monolayer concentration of the solute on the solid. When values of $\mathrm{K}$ are large, the solute-solid interactions are strong. This is the case for essential oil extraction from herbs and leaves (Roy et al., 1996) or caffeine extraction from coffee beans (Peker et al., 1992), On the other hand, when the value of $\mathrm{K}$ is small, the solute-solid interaction become weaker. It is possible to reach solute concentrations in the fluid phase that are close to solubility (Goto et al., 1998). Since the structure of natural materials is complex, the adsorption equilibrium parameters for canola and sesame are not available. Estimation of an equilibrium relationship might be difficult. To simplify the fitting of model parameters, we assumed that $\mathrm{C}_{\mathrm{m}}$ is equal to $\mathrm{C}_{\mathrm{S} 0}=\left(\mathrm{C}_{0} /(1-\mathrm{Ep})\right)$. Solubility of canola and sesame oil $\left(\mathrm{C}_{\mathrm{sat}}\right)$ was estimated from experimental data.

Table 2: The operational conditions and the correlated parameters of the model for canola seeds.

\begin{tabular}{|c|c|c|c|c|c|}
\hline Runs & P (MPa), & $\mathbf{T}(\mathbf{K})$ & $\begin{array}{c}D_{\text {eff }} * 10^{8} \\
\left(\mathrm{~m}^{2} / \mathrm{s}\right)\end{array}$ & $\begin{array}{c}D_{a x} * 10^{7} \\
\left(\mathrm{~m}^{2} / \mathbf{s}\right)\end{array}$ & $\begin{array}{c}\mathbf{k}_{\mathrm{f}} * 10^{5} \\
\left(\mathrm{~m}^{2} / \mathrm{s}\right)\end{array}$ \\
\hline 1 & 20 & 313,4 & 0.012 & 0.61 & 0.074 \\
\hline 2 & 18 & 313,4 & 0.11 & 0.48 & 1.5 \\
\hline 3 & 15 & 313,4 & 2.49 & 0.40 & 5 \\
\hline 4 & 12 & 313,4 & 3.38 & 0.391 & 9 \\
\hline 5 & 20 & 323,4 & 0.0448 & 0.34 & 0.66 \\
\hline 6 & 20 & 333,4 & 0.0466 & 0.263 & 0.71 \\
\hline 7 & 20 & 313,3 & 0.0107 & 0.60 & 0.062 \\
\hline 8 & 20 & 313,2 & 0.0102 & 0.612 & 0.064 \\
\hline
\end{tabular}

Table 3: The operational conditions and the correlated parameters of the model for sesame seeds.

\begin{tabular}{|c|c|c|c|c|c|}
\hline Runs & P (MPa), & $\mathbf{T}(\mathbf{K})$ & $\begin{array}{c}D_{\text {eff }} * 10^{8} \\
\left(\mathrm{~m}^{2} / \mathrm{s}\right)\end{array}$ & $\begin{array}{c}D_{a x} * 10^{7} \\
\left(\mathrm{~m}^{2} / \mathrm{s}\right)\end{array}$ & $\begin{array}{l}k_{\mathrm{f}} * 10^{5} \\
\left(\mathrm{~m}^{2} / \mathrm{s}\right)\end{array}$ \\
\hline 1 & 20 & 313,4 & 0.12 & 0.32 & 0.051 \\
\hline 2 & 18 & 313,4 & 0.91 & 0.27 & 1.2 \\
\hline 3 & 15 & 313,4 & 2.37 & 0.22 & 4.7 \\
\hline 4 & 12 & 313,4 & 3.39 & 0.17 & 6.2 \\
\hline 5 & 20 & 323,4 & 4.48 & 0.305 & 0.53 \\
\hline 6 & 20 & 333,4 & 4.6 & 0.25 & 0.73 \\
\hline 7 & 20 & 313,3 & 0.96 & 0.315 & 0.052 \\
\hline 8 & 20 & 313,2 & 0.904 & 0.313 & 0.0513 \\
\hline
\end{tabular}


The operational conditions for each experiment are given in Tables 2 and 3 for canola and sesame seeds, respectively. The measured yield of oil extraction (Yield) is defined by the following equation:

Yield $(\%)=\frac{\text { extracted }}{\text { total }} * 100$

Yield of oil extraction $(\%)=$

$\frac{\text { Mass of oil extracted }}{\text { Mass of oil in seeds }} \times 100$

\section{The Effect of Pressure}

Figures 2 and 3 show the effect of the pressure of the extraction on yield for canola and sesame oil, respectively. For both seeds the extraction yield increased with increasing pressure, especially at higher pressures. A faster extraction rate at low extraction times was observed when the pressure increased. As can be seen in Tables 2 and 3, at constant temperature the mass transfer coefficient decreased but the solubility of the oil increased with increasing pressure, so supercritical fluid did not disperse into the seed particle easily. The saturation concentration of oil in the fluid phase (solubility) showed a positive effect on the extraction process. On the contrary, decreasing the mass transfer coefficient showed a negative effect (Esquivel et al., 1999; Papamichail et al., 2001; Fatemi et al., 2008; Louli et al., 2004). The values of the parameters of the model and parameters of the isotherms for every operating condition are listed in Tables 2-3 and Table 4 , respectively. The effective diffusivity and film mass transfer coefficients decreased with increasing pressure because with increased pressure, binary diffusivity decreased but the axial dispersion coefficient increased (Fatemi et al., 2008). The results indicate that increasing the operating pressure for canola and sesame from 10 to $20 \mathrm{MPa}$ increases the extraction yield significantly (143.3\% and $176.7 \%$, respectively).

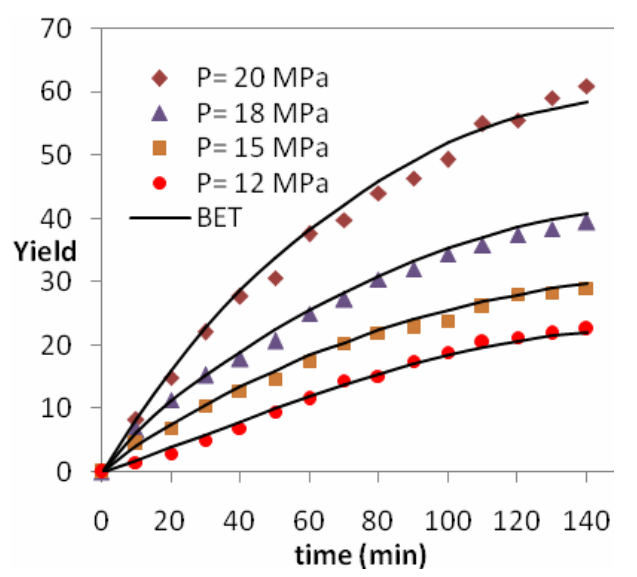

Figure 2: The effect of pressure on the yield of oil extraction from sesame at $\mathrm{T}=313 \mathrm{~K}$ and flow rate 4 gram $/ \mathrm{min}$.

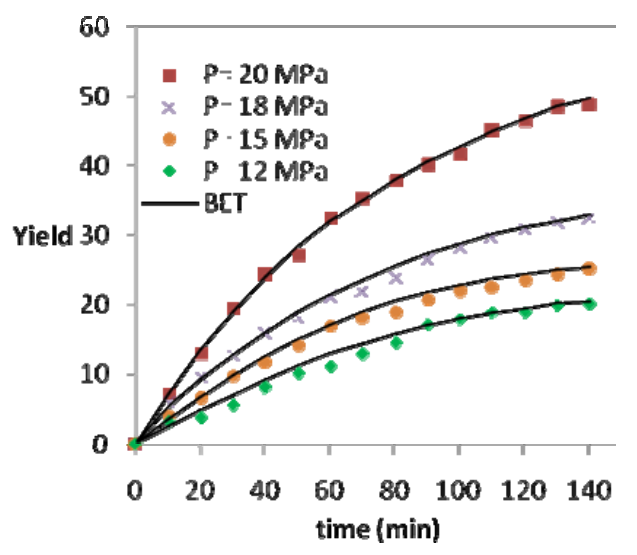

Figure 3: The effect of pressure on the yield of oil extraction from canola at $\mathrm{T}=313 \mathrm{~K}$ and flow rate $4 \mathrm{gram} / \mathrm{min}$.

Table 4: Adsorption isotherm parameters for both seeds.

\begin{tabular}{|c|c|c|c|c|c|c|c|c|c|}
\hline \multirow{3}{*}{\multicolumn{2}{|c|}{\begin{tabular}{|c|} 
Seeds \\
Isotherms \\
Parameters of isotherm
\end{tabular}}} & \multicolumn{4}{|c|}{ Canola } & \multicolumn{4}{|c|}{ Sesame } \\
\hline & & \multirow{2}{*}{$\frac{\text { linear }}{\mathrm{H}}$} & \multicolumn{2}{|c|}{ Freundlich } & \multirow{2}{*}{$\frac{\text { BET }}{\mathrm{K}}$} & \multirow{2}{*}{$\frac{\text { linear }}{\mathrm{H}}$} & \multicolumn{2}{|c|}{ Freundlich } & \multirow{2}{*}{$\begin{array}{c}\text { BET } \\
\mathbf{K}\end{array}$} \\
\hline & & & $\mathbf{K}$ & n & & & $\mathbf{K}$ & n & \\
\hline \multirow{4}{*}{ Pressure } & 120 & 0.67 & 1.32 & 1.27 & 4.57 & 0.58 & 1.30 & 1.28 & 3.41 \\
\hline & 150 & 0.41 & 1.12 & 1.21 & 3.47 & 0.37 & 1.10 & 1.18 & 2.39 \\
\hline & 180 & 0.27 & 0.84 & 1.18 & 2.31 & 0.25 & 0.78 & 1.12 & 1.82 \\
\hline & 200 & 0.13 & 0.72 & 1.08 & 1.24 & 0.10 & 0.60 & 1.09 & 1.07 \\
\hline \multirow{3}{*}{ Temperature } & 313 & 0.13 & 0.72 & 1.08 & 1.24 & 0.10 & 0.60 & 1.09 & 1.07 \\
\hline & 323 & 0.21 & 0.81 & 1.11 & 3.31 & 0.20 & 0.77 & 1.14 & 2.18 \\
\hline & 333 & 0.37 & 0.92 & 1.13 & 2.42 & 0.35 & 0.82 & 1.17 & 3.13 \\
\hline \multirow{3}{*}{ Flow rate } & 2 & 0.18 & 0.75 & 1.13 & 3.27 & 0.16 & 0.75 & 1.13 & 1.09 \\
\hline & 3 & 0.15 & 0.78 & 1.12 & 2.26 & 0.13 & 0.65 & 1.12 & 1.11 \\
\hline & 4 & 0.13 & 0.72 & 1.08 & 1.24 & 0.10 & 0.60 & 1.09 & 1.07 \\
\hline
\end{tabular}




\section{The Effect of Temperature}

The effect of temperature on extraction yield for both seeds at a pressure $20 \mathrm{MPa}$, particle size of $0.15 \mathrm{~mm}$ and $\mathrm{CO}_{2}$ flow rate of $4 \mathrm{gram} / \mathrm{sec}$ are shown in Figures 4 and 5. The extraction yield increased with decreasing temperature. The mass transfer coefficient and effective diffusivity increased but solubility of oil decreased with increasing temperature. The increasing temperature causes a decrease in solvent density and an increase in vapor pressure. In addition, under these conditions the change of solvent density is more effective than solute vapor pressure (Kandiah et al.; 1990; Esquivel et al., 1999; Papamichail et al., 2001; Louli et al., 2004). In this case of canola seeds, experimental measurements show that a temperature of $313 \mathrm{~K}$ results in a higher extraction yield by $44.25 \%$ compared to that obtained at $333 \mathrm{~K}$. The experimental results of sesame show that, upon increasing the temperature from 313 to $333 \mathrm{~K}$, the yield of

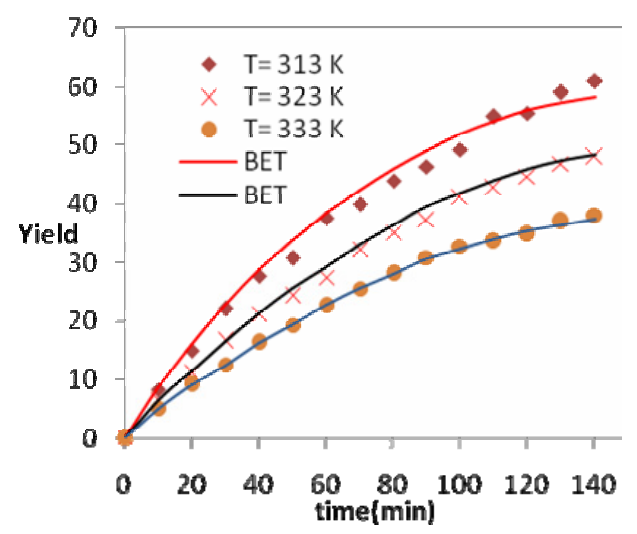

Figure 4: The effect of temperature on the extraction yield of oil from sesame at $\mathrm{P}=20 \mathrm{MPa}$ and flow rate $4 \mathrm{~g} / \mathrm{min}$.

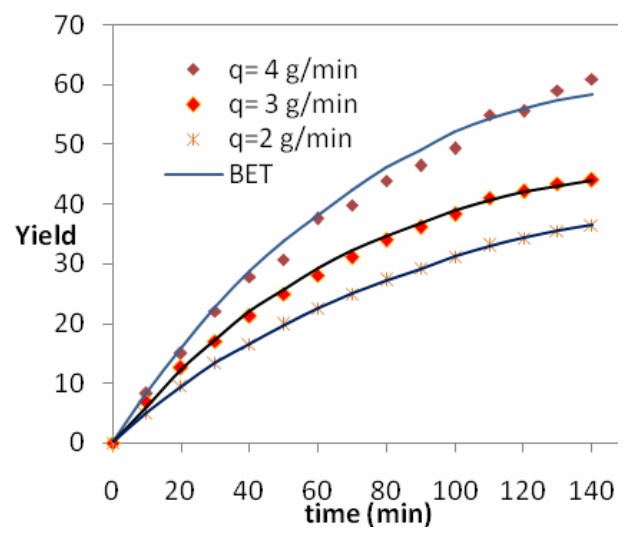

Figure 6: The effect of flow rate on the yield of oil from sesame at $\mathrm{P}=20 \mathrm{MPa}$ and $\mathrm{T}=313 \mathrm{~K}$. extraction of oil decreased $63.24 \%$.

\section{The Effect of Flow Rate}

The effect of $\mathrm{CO}_{2}$ flow rate on the extraction rate using supercritical $\mathrm{CO}_{2}$ was studied at pressure of $20 \mathrm{MPa}$ and temperature of $313 \mathrm{~K}$. Figures (6 and 7) show the effect of $\mathrm{CO}_{2}$ flow rate on the extraction rate from canola and sesame, respectively. The amount of the total oil extracted increased slightly with increasing $\mathrm{CO}_{2}$ flow rate and tend toward the same value at higher $\mathrm{CO}_{2}$ consumption. Increasing the flow rate from 2 to $4(\mathrm{~g} / \mathrm{min})$ caused a rise $(41 \%$ and $67.58 \%$, respectively) in the yield of oil extraction from canola and sesame. The increasing flow rate generally caused a shorter residence time, but the number of $\mathrm{CO}_{2}$ molecules contacting with the solute and the number of $\mathrm{CO}_{2}$ molecules per unit volume entering the extractor increased, thus increasing inter-molecular interaction between $\mathrm{CO}_{2}$ and solute, increasing the solute dissolution.

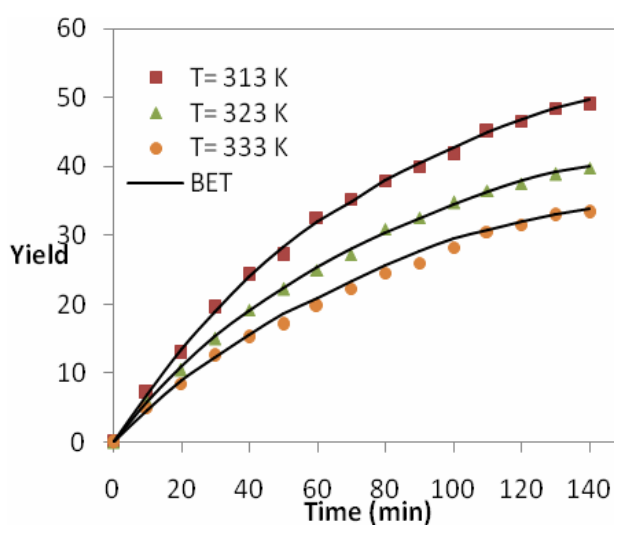

Figure 5: The effect of temperature on the extraction yield of oil from canola at $\mathrm{P}=20 \mathrm{MPa}$ and flow rate $4 \mathrm{~g} / \mathrm{min}$.

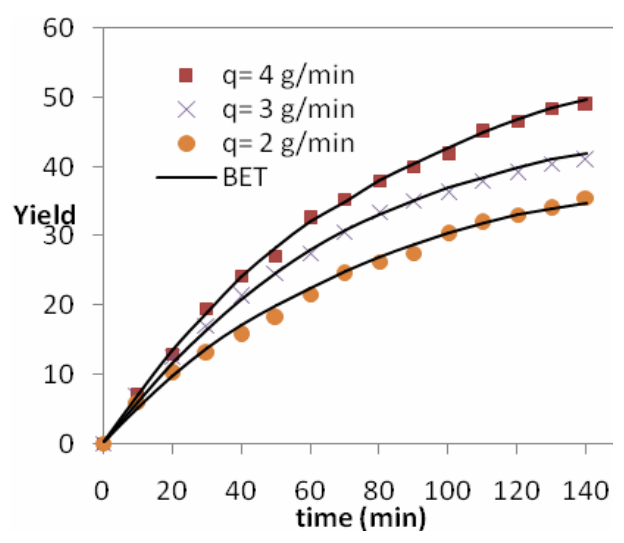

Figure 7: The effect of flow rate on the yield of oil from canola at $\mathrm{P}=20 \mathrm{MPa}$ and $\mathrm{T}=313 \mathrm{~K}$. 


\section{CONCLUSIONS}

The extraction of oil from sesame and canola seeds and mathematical modeling were evaluated. Pressure, temperature and flow rate were selected as the parameters influencing the extraction process. The results indicated that the extraction yield versus time was significantly affected by the pressure; however, temperature and flow rate have slight effect on the extraction rate. The results showed that increasing the pressure from 10 to $20 \mathrm{MPa}$ and the flow rate from 2 to $4 \mathrm{~g} / \mathrm{min}$ increased the extraction yield and increasing the temperature from 313 to $333 \mathrm{~K}$ decreased the extraction yield. The extraction yields of sesame seeds were higher than those of canola seeds at the same operating conditions. The amounts of oil extracted from these two seeds are different. The physical structure of canola seeds is much harder than sesame seeds. A theoretical twophase model based on differential mass balance within the particle pores and packed bed extractor has been studied. Adjustable parameters of the model were the effective diffusivity $\left(\mathrm{D}_{\mathrm{eff}}\right)$, mass transfer coefficient $\left(\mathrm{K}_{\mathrm{f}}\right)$ and axial dispersion coefficient $\left(\mathrm{D}_{\mathrm{ax}}\right)$ of the bed. Effective diffusivity and mass transfer coefficient decreased with increasing pressure, decreasing binary diffusivity and increasing the axial dispersion coefficient. The effect of temperature on the adjustable parameters was against the effect of pressure. The results showed that increasing $\mathrm{SC}-\mathrm{CO} 2$ flow rate caused a decreased axial dispersion coefficient and other parameters did not exhibit significant changes. To describe the distribution of solute between the solid phase and supercritical phase, Henry, Freundlich and BET isotherms were used. The BET isotherm showed good agreement with experimental data and a lower AARD. $C_{m}$ and $\mathrm{K}$ are BET constants determined by fitting with experimental data. Increasing pressure and flow rate led to a reduction of the parameter $\mathrm{K}$, but increasing the temperature caused an enhancement of $\mathrm{K}$ (Table 4). We assumed $\mathrm{C}_{\mathrm{m}}$ is equal to $\mathrm{C}_{\mathrm{s} 0}$. The best conditions of extraction of oil for both seeds were a pressure of $20 \mathrm{MPa}$, temperature of $313 \mathrm{~K}$ and flow rate of $4 \mathrm{~g} / \mathrm{min}$.

\section{NOMENCLATURE}

$a_{f} \quad$ Specific surface of the solid

C Solute concentration in the bulk phase

$\mathrm{C}_{\mathrm{p}} \quad$ Solute concentration in the pore volume

\begin{tabular}{|c|c|c|}
\hline $\mathrm{C}_{\mathrm{p}, 0}$ & $\begin{array}{l}\text { Solute concentration in the } \\
\text { pore volume at } \mathrm{t}=0\end{array}$ & $\mathrm{~mol} \mathrm{~m}{ }^{-3}$ \\
\hline $\mathrm{C}_{\mathrm{m}}$ & Parameter in BET isotherm & \\
\hline $\mathrm{C}_{\mathrm{s}}$ & $\begin{array}{l}\text { Solute concentration in the } \\
\text { solid }\end{array}$ & $\mathrm{mol} \mathrm{m}^{-3}$ \\
\hline $\mathrm{C}_{\mathrm{s}, 0}$ & $\begin{array}{l}\text { Solute concentration in the } \\
\text { solid at } \mathrm{t}=0\end{array}$ & $\mathrm{~mol} \mathrm{~m}^{-3}$ \\
\hline $\mathrm{C}_{0}$ & Total solute concentration & \\
\hline $\mathrm{D}_{\mathrm{ax}}$ & Axial dispersion coefficient & $\mathrm{m}^{2} / \mathrm{s}$ \\
\hline $\mathrm{D}_{\mathrm{eff}}$ & Effective diffusivity & $\mathrm{m}^{2} / \mathrm{s}$ \\
\hline $\mathrm{D}_{\mathrm{AB}}$ & Diffusion coefficient & $\mathrm{m}^{2} / \mathrm{s}$ \\
\hline $\mathrm{k}_{\mathrm{f}}$ & Mass transfer coefficient & $\mathrm{m}^{2} / \mathrm{s}$ \\
\hline $\mathrm{H}$ & Henry coefficient & \\
\hline $\mathrm{K}$ & Equilibrium constant & \\
\hline $\mathrm{L}$ & Bed length & $\mathrm{m}$ \\
\hline $\mathrm{N}$ & $\begin{array}{l}\text { Parameter in Freundlich } \\
\text { isotherm }\end{array}$ & \\
\hline $\mathrm{Pe}$ & Peclet number & $\mathrm{u}_{0} \mathrm{~L} / \mathrm{D}_{\mathrm{ax}}$ \\
\hline $\mathrm{R}$ & $\begin{array}{l}\text { Radial distance coordinate } \\
\text { in particle }\end{array}$ & $\mathrm{m}$ \\
\hline $\mathrm{R}_{\mathrm{p}}$ & Particle radius & $\mathrm{m}$ \\
\hline $\mathrm{Re}$ & Reynold number & \\
\hline $\mathrm{Sc}$ & Schmidt number & \\
\hline $\mathrm{Sh}$ & Sherwood number & \\
\hline $\mathrm{T}$ & Time & \\
\hline $\mathrm{U}$ & Superficial velocity of $\mathrm{CO}_{2}$ & \\
\hline Z & Axial distance & \\
\hline
\end{tabular}

\section{Greek Letters}

$\varepsilon_{\mathrm{b}} \quad$ Void bed fraction

$\varepsilon_{\mathrm{p}} \quad$ Void fraction of particle

\section{REFERENCES}

Barroso, M. S. T., Villanueva, G., Lucas, A. M., Perez, G. P., Vargas, R. M. F., Brun, G. W., Cassel, E., Supercritical fluid extraction of volatile and non-volatile compounds from Schinus molle L. Braz. J. Chem. Eng., vol. 28, n. 2, pp. 305-312 (2011).

Bartle, K. D., Clifford, A. A., Hawthorne, S. B., Langenfeld, J. J., Miller, D. J., Robinson, R. A., A model for dynamic extraction using a supercritical fluid. J. Supercrit. Fluids, vol. 3, pp. 143-149 (1990).

Carvalho, R. H. R., Galvao, E. L., Barros, J. A. C., Conceicao, M. M., Souza, E. M. B. D., Extraction fatty acid profile and antioxidant activity of sesame extract (Sesamum Indicum L.). Braz. J. Chem. Eng., vol. 29, n. 2, pp. 409-420 (2012).

Esquivel, M. M., Bernardo-Gil, M. G., King, M. B., Mathematical models for supercritical extraction 
of olive husk oil. J. Supercritical Fluids, vol. 16, pp. 43-58 (1999).

Garcia-Risco, M. R., Hernandez, E. J., Vicente, G., Fornari, T., Senorans, F. J., Reglero, G., Kinetic study of pilot-scale supercritical $\mathrm{CO}_{2}$ extraction of rosemary (Rosmarinus officinalis) leaves. J. Supercritical Fluids, vol. 55, pp. 971-976 (2011).

Ghoreishi, S. M., Sharifi, S., Modeling of supercritical extraction of Mannitol from plane tree leaf. J. Pharmaceut. Biomed. Anal., vol. 24, pp. 10731048 (2001).

Goodarznia, I., Eikani, M. H., Supercritical carbon dioxide extraction of essential oils: Modeling and simulation. Chem. Eng. Sci., vol. 53, pp. 13871395 (1998).

Goto, M., Roy, B. C., Kodama, A., Hirose, T., Modeling supercritical fluid extraction process involving solute-solid interaction. J. Chem. Eng. Jpn., vol. 31, pp. 171-177 (1998).

Ivanovic, J., Ristic, M., Skala, D., Supercritical $\mathrm{CO}_{2}$ extraction of Helichrysum italicum: Influence of $\mathrm{CO}_{2}$ density and moisture content of plant material. J. Supercritical Fluids, vol. 57, pp. 129136 (2011).

Kandiah, M., Spiro, M., Extraction of ginger rhizome - kinetic-studies with supercritical carbon dioxide. Int. J. Food Sci. Technol., vol. 25, pp. 328-338 (1990).

Louli, V., Folas, G., Voutsas, E., Magoulas, K., Extraction of parsley seed oil by supercritical $\mathrm{CO}_{2}$. J. Supercritcal Fluids, vol. 30, pp. 163-174 (2004).

Naik, S. N., Lentz, H., Maheshwari, R. C., Extraction of perfumes and flavours from plant materials with liquid carbon dioxide under liquid-vapor equilibrium conditions. Fluid Phase Equilibria, vol. 49, pp. 115-124 (1989).

Nguyen, K., Barton, P., Spencer, J. S., Supercritical carbon dioxide extraction of vanilla. J. Supercritical. Fluids, vol. 4, pp. 40-46 (1991).

Papamichail, V., Louli, K., Magoulas, K., Supercritical fluid extraction of celery seed oil. J. Supercritcal Fluids, vol. 18, pp. 213-226 (2000).

Peker, H., Srinivasan, M. P., Smith, J. M., McCoy, B. J., Caffeine extraction rates from coffee beans with supercritical carbon dioxide. AIChE J., vol. 38, n. 5, pp. 761-770 (1992).

Penedo, P. L., Coelho, G. L .V. and Mendes, M. F., Phase equilibria of oleic, palmitic, stearic, linoleic and linolenic acids in supercritical $\mathrm{CO}_{2}$. Braz. J. Chem. Eng., vol. 26, n. 1, pp. 137-142 (2009).

Perrut, M., Clavier, J. Y., Poletto, M., Reverchon, E., Mathematical modeling of sunflower seed extraction by supercritical $\mathrm{CO}_{2}$. Ind. Eng. Chem. Res., vol. 36, pp. 430- 437 (1997).

Poling, B. E., Prausnitz, J. M., O'Connell, J. P., The Properties of Gases and Liquids. Fifth Ed., McGraw-Hill Co. Inc., New York (2001).

Reverchon, E., Donsi, G., Osseo, L. S., Modeling of supercritical fluid extraction from herbaceous matrices. Ind. Eng. Chem. Res., vol. 32, pp. 27212726 (1993).

Reverchon, E., Marrone, C., Modeling and simulation of the supercritical $\mathrm{CO}_{2}$ extraction of vegetable oils. J. Supercrit. Fluids, vol. 19, pp. 161-175 (2001).

Rincon, J., Martinez, F., Rodriguez, L., Ancillo, V., Recovery of triglycerides from used frying oil by extraction with liquid and supercritical ethane. J. Supercritical Fluids, vol. 56, pp. 72-79 (2011).

Roy, C., Goto, M. and Hirose, T., Extraction of ginger oil with supercritical carbon dioxide: Experiments and modeling. Industrial \& Engineering Chemistry Research, vol. 35, pp. 607-612 (1996).

Salami, A., Fatemi, Sh., Zakizadeh Nei Nei, H., Safaralie, A., Mathematical modeling of supercritical of valerenic acid from Valeriana officinalis L. Chem. Eng. Technol., vol. 31, n. 10, pp. 1470-1480 (2008).

Silva, C. F., Mendes, M. F., Pessoa, F. L. P., Queiroz, E. M., Supercritical carbon dioxide extraction of macadamia (Macadamia integrifolia) nut oil: Experiments and modeling. Braz. J. Chem. Eng., vol. 25, n. 1, pp. 175-181 (2008).

Silva, C. F., Moura, F. C., Mendes, M. F., Pessoa, F. L. P., Extraction of citronella (Cymbopogon nardus) essential oil using supercritical $\mathrm{CO}_{2}$ : Experimental data and mathematical modeling. Braz. J. Chem. Eng., vol. 28, n. 2, pp. 343-350 (2008).

Sovová, H., Rate of the vegetable oil extraction with supercritical $\mathrm{CO}_{2}-\mathrm{I}$ Modeling extraction curves. Chem. Eng. Sci., vol. 49, pp. 409-419 (1994).

Sovová, H., Kucera, J., Jez, J., Rate of the vegetable oil extraction with supercritical $\mathrm{CO}_{2}-$ II. Extraction of grape oil. Chem. Eng. Sci. vol. 49, pp. 415-420 (1994).

Subra, P., Castellani, S., Jestin, P., Aoufi, A., Extraction of - carotene with supercritical fluids experimental and modeling. J. Supercritical Fluids, vol. 12, pp. 261-269 (1998).

Tan, C. S., Liou, D. C., Axial dispersion of supercritical carbon dioxide in packed beds. Ind. Eng. Chem. Res., vol. 28, pp. 1246-1250 (1989).

Tan, C. S., Liou, D. C., Modeling of desorption at supercritical condition. AIChE J., vol. 35, pp. 1029-1031 (1989). 